\section{Brief visual memory for English and Arabic letters*}

\author{
DENNIS H. HOLDING $\dagger$ \\ University of Louisville, Louisville, $\mathrm{Ky} .40208$
}

American and Arabic Ss were asked to make whole and partial reports on briefly presented letter arrays in English and Arabic script. None of the ratios between whole and partial report suggests the availability of excess sensory storage. For the Arab Ss, who were bilingual to varying degrees, comparison of the scripts was ambiguous. The American Ss had access to over three familiar letters in whole report, as expected, but were able to report less than one of the Arabic symbols. These results appear counter to the visual storage hypothesis.

The hypothesis of visual information storage (Sperling, 1960, 1963; Neisser, 1967) has two main features. The first is that the capacity of visual storage, accessible by sampling subsequent to the brief presentation of stimulus material, is thought greatly to exceed the capacity of normal short-term memory mechanisms. The second, and separable, feature is that storage is thought to take the form of sensory persistence, perhaps as a rapidly decaying visual image.

The existence of the postulated excess capacity has been called in question by evidence (Holding, 1970, 1971) that suggests that $S$ s are able to see only those letters that they select for attention. The second feature remains a theoretical possibility, in that those letters that are eventually reported might have been held temporarily in a visual form prior to recoding. Work using recognition techniques (Holding, in press) indicates that this is unlikely, although Tversky (1969) has reported that visual encoding may be selected after longer exposures.

An obvious further check on the hypothetical visual properties of temporary storage is to investigate the immediate recall of foreign, rather than familiar, letter arrays. Clearly, if symbols for which Ss have no linguistic equivalents are presented, recall must be biased toward visual storage. Some verbal labeling of the shape elements that compose the letters may be possible, but this will be a cumbersome and inefficient method of retention in comparison with the storage of a visual representation, which should give relatively high letter scores.

The Arabic alphabet provides suitable material for investigation. It

* Thanks are due to Fawziyah Mulla-Husain for assistance in both data collection and scoring.

tRequests for reprints should be sent to Dennis H. Holding, Department of Psychology, University of Louisville, Louisville, Ky. 40208 . consists of 27 letters, which may take initial, medial, or terminal forms. Most of these are simple, resembling shorthand symbols, and are therefore easily written by Western Ss. The same alphabet is used throughout the Arab world, with the advantage that groups of Ss may be assembled from the nationals of a variety of Middle Eastern countries. In the present experiment, an Arab group was used in addition to American $\mathrm{Ss}$, in order to estimate the effects of linguistic familiarity. Both groups were tested for partial and for whole recall of letter arrays, both in English and in Arabic script.

The American Ss were eight freshmen serving for credit in introductory psychology courses. The eight Arab Ss were recruited from the University International Center and were at varying academic levels in subjects other than psychology. All were practically bilingual, with residence of 1 to 9 years, with a mean Canada.

\section{APPARATUS AND MATERIALS}

The stimulus arrays were all of 12 letters, arranged in three rows of four letters each. As displayed in a Polymetric (V-09597) tachistoscope, the array dimensions were approximately $5 \times 6 \frac{1}{1} 2 \mathrm{deg}$ of visual angle. The English letter displays were 40 photographic enlargements of typewritten cards, each consisting of random selections of the 20 consonants, excluding "Y," with the constraint that no letter appeared twice on the same card.

The 40 Arabic letter arrays were stencilled in black ink to the same dimensions as the English letters. In this case, the pool of 20 letters, from which selections corresponding to the English arrays were made, was partly determined by discriminability. As some initial forms of Arabic letters differ only in the number or presence of auxiliary dots, or were judged by the $E$ likely to cause difficulties in scoring, a residual pool of 17 initial of 4 years, in the United States or letters was supplemented by the use of three medial forms.

Exposure duration was always $50 \mathrm{msec}$, with a dark pre- and postexposure field. For partial reports, the stimulus exposure was immediately followed by a 0.5 -sec cue tone, supplied to a speaker located underneath the tachistoscope. A tone of $2,500 \mathrm{~Hz}$ was used to elicit reports on the top row of letters, $800 \mathrm{~Hz}$ for the middle, and $250 \mathrm{~Hz}$ for the bottom row. All cue sequences were random, with no constraint due to equating the frequencies of presentation of high, middle, or low tones.

\section{DESIGN AND PROCEDURE}

All $16 \mathrm{Ss}$ attended for two sessions on separate days and were later recalled for a supplementary test of reading speeds. The first day provided for instructions, apparatus familiarization, and practice on all conditions; the substantive data were collected in the second session. In each session, whole and partial reports were elicited in separate blocks of 10 cards in each language type. Each exposure was triggered by $S$ when ready. For whole reports, Ss were instructed to write as many as possible of the stimuli onto $3 \times 4$ array blanks immediately after the exposure. For the partial reports, only those letters in the row indicated by the cuing tone were to be reported. The order of presentation of language types, and of whole or partial report blocks within language types, was counterbalanced across Ss.

In the supplementary session, Ss were timed while reading aloud as fast as possible. Each $\mathrm{S}$ read four sets of 10 practice and test cards in owe or both languages. The Arab Ss read two sets in each language, while the American Ss read only in English.

\section{RESULTS}

As in previous work, all scoring was in terms of correct letters in the correct position. Mean letters correct per array, together with standard deviations, are shown in Table 1. In each language and script condition, the partial report scores appear slightly greater than one-third the whole report scores. Statistical comparisons have been based on the figures for whole report. The American Ss' mean of 3.20 for whole report on English script is close to the 3.40 and 3.25 (Holding, 1970, 1971) obtained earlier in similar circumstances. In comparison, less than one unfamiliar Arabic symbol was retained by these Ss. A Wilcoxon test confirms that these figures differ significantly $(\mathrm{p}<.01)$

The Arab group did less well than the Americans with English letters, the difference reaching borderline 
Table 1

Means and Standard Deviations for Whole and Partial Reports in All Language and Script Conditions

\begin{tabular}{llllll}
\hline & & \multicolumn{2}{c}{ English } & & \multicolumn{2}{c}{ Arabic } \\
\cline { 3 - 6 } & & Mean & SD & Mean & SD \\
\hline \multirow{2}{*}{ Americans } & Whole & 3.20 & .95 & 0.84 & .32 \\
& Partial & 1.29 & .72 & 0.32 & .26 \\
Arabs & Whole & 2.58 & .44 & 1.52 & .42 \\
& Partial & 0.93 & .27 & 0.65 & .23 \\
\hline
\end{tabular}

significance $(p=.052)$ on the Mann-Whitney test. As expected, the Arab Ss did better with the Arabic letters than the American Ss; the Mann-Whitney test confirms that this difference is significant $(p<.002)$. However, the absolute level of performance with Arabic script is surprisingly low for this group and differs significantly $(p<.01$; Wilcoxon) from their scores on the English letter arrays.

Since both American and Arab Ss scored low on Arabic letters, it was suspected that this script might be more difficult to read or to pronounce. However, the speeds for reading aloud showed no significant differences. The American group reached a speed of 0.40 sec per letter on the final set of cards ( 0.41 on the second test). For the Arab Ss, the second set of each language yielded the test data, with mean of 0.40 in English and 0.43 in Arabic.

\section{DISCUSSION}

Nothing in the data lends credence to the visual storage hypothesis. Although the American Ss scored within the normal range for English letters, they were unable to reproduce reliably a single unfamiliar Arabic symbol. It is possible to argue that the postulated image might have faded before more letters could be reported, but the quantitative justification for this assumption is difficult to specify. It seems unlikely that even the degraded traces of 10 or 12 letters should be beyond reconstruction to the extent observed. The effect could not have been due to the complexity of the symbols or to motor difficulties in reproducing them, since most of the characters require only a single stroke of the pen.

The most parsimonious explanation derives from assuming that visual information is processed immediately, rather than remaining as a passive sensory trace. In the case of the familiar letters, processing will consist essentially of activating linguistic equivalents for the symbols, perhaps in an acoustic form. For the unfamiliar characters, processing will depend upon pattern analysis and classification. Under these circumstances, the processing demands imposed by a single unfamiliar symbol apparently exceed the capacity normally adequate for the registration of three or four familiar letters.

The ratio of partial to whole report scores shows no evidence of the excess capacity postulated by Sperling (1960), although the same exposure duration and display size were used. Multiplying the partial report scores by three, the number of cued alternatives, produces a fractional excess over whole report that is far less than the nearly total availability predicted by the visual storage hypothesis. The difference is comparable to that observed earlier (Holding, 1970), and is readily explicable in terms of the interference imposed by the act of reporting. As Anderson (1960) observed, the greater absolute number of responses required by whole reports gives rise to more interference with recall than in the case of the partial reports, thus somewhat depressing the whole report scores.

The relatively low Arabic scores of the Arab Ss appear not to be explained by differences in reading speed, although there are some differences in the phonetic demands of the two alphabets. Both languages have only one multisyllabic letter, the "W" of English being matched by "aleph" in Arabic. However, all other English letters are pronounced with one or no consonants; while approximately half the Arabic letters take a CVC form, as in "mim" or "sein," which may add fractionally to the pronunciation time.

What may be more important is the set of the Arab Ss toward the task. All were trying to become fluent in English, inhibiting Arabic responses in daily life, and it is possible that the tendency toward suppression of Arabic was carried into the experimental situation. It is at least suggestive that the group did not unanimously report the letters in the expected right-to-left order. Three of the eight reported in the Western left-to-right order, and two Ss were inconsistent. It is clear, therefore, that practice in reading English has produced some interference with normal Arabic reading habits. If this effect is responsible for the observed results, higher report scores are to be expected from native speakers having only Arabic.

While there may be some doubt concerning the degree of development of linguistic habits in the Arab Ss, the American Ss provide an unambiguous comparison of the two scripts. For these Ss, a familiar linguistic code is contrasted with a totally unfamiliar code, producing widely divergent results. Since both forms of script should lend themselves to visual trace formation with equal facility, it must be concluded that any simple form of the visual storage hypothesis is untenable.

\section{REFERENCES}

ANDERSON, N. S. Poststimulus cuing in immediate memory. Journal of Experimental Psychology, 1960, 60, 216-221.

HOLDING, D. H. Guessing behavior and the Sperling store. Quarterly Journal of Experimental Psychology, 1970, 22, 248-256.

HOLDING, D. H. The amount seen in brief exposures. Quarterly Jourmal of Experimental Psychology, 1971, 23, 72-81.

HOLDING, D. H. Recognition tests of visual information storage. British Journal of Psychology, in press.

NEISSER, U. Cognitive psychology. New York: Appleton-Century-Crofts, 1967.

SPERLING, G. The information available in brief visual presentations. Psychological Monographs, 1960,74 , Whole No. 498.

SPERLING, G. A model for visual memory tasks. Human Factors, 1963, 5, 19-31.

TVERSKY, B. Pictorial and verbal encoding in a short-term memory task. Perception \& Psychophysics, 1969, 6, 225-233. 